\title{
Primeiro Registro de Bothriochloa Kuntze (Poaceae - Panicoideae - Andropogoneae) para a Ilha de Santa Catarina, Brasil
}

\author{
Bárbara Toncic Neves ${ }^{1}$ \& Ana Zanin ${ }^{2}$
}

Enviado em abril de 2011; aceito em junho de 2011.

\section{Resumo}

A presença do gênero Bothriochloa Kuntze é registrada pela primeira vez para a Ilha de Santa Catarina com a ocorrência de dois táxons nativos: Bothriochloa exaristata (Nash) Henrard e B. laguroides (DC.) Herter var. laguroides. Ambos ocorrem especialmente em áreas urbanizadas como estacionamentos, margens de caminhos e gramados. B. laguroides var. laguroides apresenta o hábito frequentemente semidecumbente com folhas concentradas na base e espiguetas sésseis aristadas e com lema superior presente. Em B. exaristata o hábito é cespitoso-ereto ou semidecumbente e as folhas caulinares mais longas e estreitas do que no táxon anterior e as espiguetas sésseis são múticas com lema superior ausente. O trabalho apresenta descrições, ilustrações e informações sobre distribuição geográfica, hábitat e período de floração dos dois táxons.

Palavras-chave: Bothriochloa laguroides var. laguroides, Bothriochloa exaristata, Gramineae, biodiversidade, florística.

\section{Abstract}

[First record of Bothriochloa Kuntze (Poaceae - Panicoideae - Andropogoneae) for Santa Catarina Island, Brazil]. The presence of Bothriochloa Kuntze is reported for the first time for Santa Catarina Island where there are two native taxa: $B$. laguroides (DC.) Herter var. laguroides and B. exaristata (Nash) Henrard. Both occur mostly in urban areas, such as parking lots, the margins of paths, and lawns. Bothriochloa laguroides var. laguroides often has a semi-decumbent habit with leaves

Doi: 10.5007/2178-4574.2011v40p5

${ }^{1}$ Programa de Pós-Graduação em Biologia Vegetal, Universidade Federal de Santa Catarina, Florianópolis, 88040-900, Brasil.

${ }^{2}$ Departamento de Botânica - UFSC - PPGBVE, Trindade, Florianópolis, Santa Catarina, 88040-900, Brasil.

${ }^{3}$ Autor para correspondência: anazanin@ccb.ufsc.br

\section{(cc) $\mathrm{BY}-\mathrm{NC}$} permite uso não-comercial, distribuição e reprodução em qualquer meio, desde que este trabalho original seja devidamente citado. 
that are concentrated at the base of the plant and sessile spikelets with awns and upper lemma. B. exaristata has a caespitose-erect or semi-decumbent habit with longer narrower leaves on the stem and sessile spikelets that are muticous and lack upper lemma. Descriptions, illustrations, ecological comments and distribution are provided for each taxon.

Key words: Bothriochloa laguroides var. laguroides, Bothriochloa exaristata, flora, Gramineae, biodiversity.

\section{Introdução}

O gênero Bothriochloa possui cerca de 35 espécies distribuídas através dos trópicos (Clayton \& Renvoize 1986; Vega 2000). Para o Brasil, Marchi \& LonghiWagner (1998) mencionaram a ocorrência de 14 táxons, cinco deles para o estado de Santa Catarina e Valls (2010) 13, com o mesmo número para SC. Por outro lado, Smith et al. (1982) referiram apenas uma espécie para o Estado, B. saccharoides (Sw.) Rydb., com base em material de B. laguroides var. torreyana (Steud.) M. Marchi \& Longhi-Wagner (Marchi \& Longhi-Wagner 1998), sendo B. saccharoides não confirmada.

Há poucos registros para o gênero Bothriochloa em Santa Catarina, sendo estes associados especialmente a campos de altitude. Para $B$. laguroides var. laguroides, até o momento, havia menção apenas para o planalto sul, e para $B$. exaristata, um registro para o meio-oeste e três para os solos arenosos do litoral. Entre os últimos, há duas referências (Kornelius s.n.- BLA 6832, 10748) para "Praia de Cabeçudas" pertencente ao município de Itajaí, citadas de forma errônea para Florianópolis (Marchi \& Longhi-Wagner 1998).

O trabalho apresenta chave, descrições, ilustrações e dados referentes à distribuição geográfica, preferências ambientais e período de floração dos táxons.

\section{Material e Métodos}

A Ilha de Santa Catarina localiza-se no município de Florianópolis, no Estado de Santa Catarina e abrange uma área de cerca de $423 \mathrm{Km}^{2}$, entre as latitudes $27^{\circ} 22^{\prime}$ e $27^{\circ} 50^{\prime} \mathrm{S}$ e as longitudes $48^{\circ} 25^{\prime}$ e $48^{\circ} 35^{\prime} \mathrm{W}$ (CECCA 1997). Apresenta formações florestais do Bioma Mata Atlântica como a Floresta Ombrófila Densa, onde o clima é o fator determinante, e ecossistemas associados como os manguezais e a vegetação de restinga, praia, dunas, e Floresta de Planícies Quaternárias, caracterizadas como Formações Vegetais Edáficas, tendo como fator dominante as condições do solo (Caruso 1990).

O estudo baseou-se em coletas, observações de populações no campo e revisão de materiais dos Herbários FLOR (Universidade Federal de Santa Catarina Florianópolis) e HBR (Barbosa Rodrigues) de Itajaí. As coletas foram realizadas entre janeiro de 2009 e março de 2010, procurando abranger todas as formações abertas da 
Ilha de Santa Catarina. O material coletado foi incorporado ao Herbário FLOR. As informações sobre hábitat e fenologia foram baseadas no material de ocorrência na Ilha de Santa Catarina e os dados sobre distribuição geográfica, na literatura e material estudado.

\section{Resultados e Discussão}

Foram registrados dois táxons de Bothriochloa para a Ilha de Santa Catarina, B. exaristata e B. laguroides var. laguroides. De acordo com Marchi \& LonghiWagner (1998), são os representantes mais comuns do gênero no Brasil e com ocorrência geralmente simpátrica. Na Ilha de Santa Catarina as populações de cada espécie foram encontradas separadas, não sendo constatada simpatria. Ambas ocorrem em ambientes alterados como beiras de estradas, gramados e barrancos, sendo que $B$. laguroides foi encontrada apenas no perímetro urbano e $B$. exaristata também em áreas rurais sob menor influência antrópica.

Bothriochloa Kuntze, Revis. Gen. Pl. 2: 762. 1891.

Plantas perenes, cespitosas, colmos eretos ou semi-decumbentes. Prefoliação convoluta. Bainhas foliares glabras ou pilosas; lâminas planas, acuminadas, glabras ou pilosas; lígula membranosa ou membranoso-ciliada. Inflorescências em panícula, com os ramos dispostos sobre um eixo principal alongado e persistente, ou subdigitados sobre um eixo principal curto; pedicelos e entrenós da ráquis delgados, com sulco hialino longitudinalmente e margens pilosas, com tricomas gradualmente maiores em direção ao ápice. Espiguetas sésseis com 2 glumas, 2 antécios hialinos, 1-floras, acrótonas, bissexuadas, múticas ou aristadas, antécio superior completo ou incompleto; gluma inferior biquilhada, geralmente coriácea, a superior uniquilhada, lema inferior mútico, pálea ausente; lema superior presente ou ausente, quando presente mútico ou aristado, pálea geralmente ausente, às vezes rudimentar e hialina. Estames 3. Espiguetas pediceladas geralmente reduzidas, neutras, raramente com flor estaminada.

\section{Chave para os táxons de Bothriochloa ocorrentes na Ilha de Santa Catarina}

1. Espiguetas sésseis múticas, lema superior ausente. 1. B. exaristata

1'. Espiguetas sésseis aristadas, lema superior presente 2. B. laguroides var laguroides

\section{Bothriochloa exaristata (Nash) Henrard, Blumea 4(3): 520. 1941.}

Plantas perenes, cespitoso-eretas ou semi-decumbentes, $50-170 \mathrm{~cm}$; colmos glabros, verdes, às vezes violáceos, 5-8 nós glabros, raramente os basais pubescentes. Bainhas foliares mais curtas que os entrenós, raramente mais longas, glabras; lâminas 9-22,4 x 0,3-0,6cm, verdes, geralmente glabras em ambas as faces, às vezes adpresso-pubescentes, margens escabras em direção ao ápice, tricomas marginais de 
5-7mm compr. na região proximal; lígula 2-4mm compr., membranosa. Inflorescências com ramos paniculados distribuídos sobre um eixo principal alongado e persistente, 6,2-11 x 0,5-3cm, branco-pilosas, com ramos geralmente alternos e com as espiguetas densamente agrupadas; pedicelos e entrenós da ráquis subiguais ou desiguais no comprimento, entrenós $2-3$ x 0,2-0,3(-0,4)mm, geralmente alargado em direção ao ápice, com sulco de $0,1(-0,2) \mathrm{mm}$ de largura, geralmente da mesma largura que as margens, estas com tricomas de 4-6(-8)mm compr., pedicelos 2,8-3,3(-3,5)mm compr. Espiguetas sésseis múticas, verdes, calo piloso, os tricomas mais longos alcançando (0,5-)1-2mm compr.; glumas inferiores 3-4 x 0,6-0,8($0,9) \mathrm{mm}$, escabras na metade superior das quilhas, com tricomas na metade inferior da região dorsal, (5)6(7)-nervadas; glumas superiores 2,5-3,4 x 0,4-0,7(-0,8)mm, escabras na metade superior da nervura central, finamente pubescente na parte superior das nervuras laterais, 3-nervadas; lema inferior 1,5-2,2 x (0,2-)0,4-0,7mm, lanceolado; pálea inferior ausente; lema superior ausente; pálea superior ausente. Cariopse 2-2,2 x 0,5-0,7mm, castanho-escura na maturação. Espiguetas pediceladas reduzidas e neutras; glumas inferiores 2,2-3,2(-4)mm compr., escabras nas quilhas e na metade superior da região dorsal; glumas superiores geralmente ausentes.

Distribui-se nos Estados Unidos, Bolívia, Argentina, Paraguai e Brasil: Mato Grosso do Sul, Minas Gerais, Rio Grande do Sul e Santa Catarina (Marchi \& LonghiWagner 1998, Flores 2001). Na Ilha de Santa Catarina é encontrada nas partes norte, centro e sul em áreas alteradas como beiras de estradas, terrenos baldios e gramados tratados, às vezes em clareiras no interior da Mata Atlântica, frequentemente em solos compactos e pedregosos. Ocorre tanto em áreas urbanizadas como no centro da cidade, quanto em áreas rurais do Morro do Ribeirão e Ratones, no sul e norte da Ilha, respectivamente. Foi encontrada com flor e/ou fruto durante todo o ano.

Bothriochloa exaristata é reconhecida pela presença de espiguetas sésseis múticas com lema superior ausente e nós geralmente glabros. Apresenta plantas relativamente mais altas, com folhas caulinares e lâminas foliares mais longas que $B$. laguroides var. laguroides. Segundo Marchi \& Longhi-Wagner (1998), B. exaristata possui hábito ereto, porém, a maioria dos espécimes coletados na Ilha apresenta hábito semi-decumbente, semelhante ao observado em B. laguroides var. laguroides.

Material examinado: BRASIL. Santa Catarina: Florianópolis, Carvoeira, 19. VI. 2009, B. Toncic \& A. Zanin 230 (FLOR); 20. VII. 2009, B. Toncic \& A. Zanin 232 (FLOR); 16. XI. 2009, B. Toncic \& A. Zanin 250 (FLOR); Ingleses, 19. IV. 2009, A. Zanin 1584 (FLOR); Itacorubi, 22. I. 1992, M. H. de Queiroz NI-51 (FLOR); Lagoa da Conceição, Praia do Gravatá, 2. II. 2010, B. Toncic \& A. S. Mello 324 (FLOR); Matadeiro, 28. III. 2010, B. Toncic \& A. Zanin 330 (FLOR); Ratones, 25. IX. 2009, B. Toncic \& A. Zanin 289 (FLOR); Ribeirão da Ilha, 23. XI. 2009, B. Toncic \& A. Zanin 280 (FLOR); Trindade, 11. V. 2009, B. Toncic \& A. Zanin 229 (FLOR). 
2. Bothriochloa laguroides (DC.) Herter var. laguroides, Revista Sudamericana de Botánica 6(5-6): 135. 1940.

Plantas perenes, semi-decumbentes ou menos frequentemente cespitosoeretas, 49-92(-100)cm; colmos glabros, verdes, 4-8 nós glabros, às vezes os basais levemente pubescentes ou pubérulos. Bainhas foliares geralmente mais longas que os entrenós, glabras; lâminas $8,5-16,7$ x 0,2-0,45cm, verdes, tornando-se vináceas na maturação, glabras ou cobertas por tricomas adpressos em ambas as faces, às vezes face adaxial escabra superiormente, margens escabras em direção ao ápice, tricomas de 8-10mm compr. esparsos na região proximal da face adaxial; lígula 1-3mm compr., membranosa. Inflorescências com ramos paniculados distribuídos sobre um eixo principal alongado e persistente, 4-8,2 x $(0,5) 1-5 \mathrm{~cm}$, branco-pilosas, com ramos geralmente alternos e com as espiguetas densamente agrupadas ou, menos frequentemente, esparsas; entrenós da ráquis e pedicelos subiguais no comprimento, entrenós 2-2,8 x 0,3-0,5mm, alargado em direção ao ápice, com sulco de 0,1-0,2($0,3) \mathrm{mm}$ de largura, geralmente mais largo do que as margens, estas com tricomas densos de 7-12mm compr., pedicelos 2-3mm compr. Espiguetas sésseis aristadas, verdes, às vezes palhetes, calo piloso, os tricomas mais longos alcançando 1-2,5(3)mm compr.; glumas inferiores 2,8-4 x 0,7-1mm, escabras no terço superior das quilhas, margens glabras, às vezes levemente ciliadas no terço superior, tricomas na região dorsal mediana, geralmente 6-nervadas; glumas superiores 2,6-3 x 0,5$0,8 \mathrm{~mm}$, escabras no terço superior das nervuras, ciliadas ou escabras nas margens e próximo a estas, 3-nervadas; lema inferior 1,3-2 x 0,5-0,7mm, lanceolado; pálea inferior ausente; lema superior 2-2,1 x 0,1-0,2mm, arista geniculada, coluna retorcida de 1,5-2mm compr., glabra ou esparsamente escabra, súbula reta de 8-13,5(15)mm compr., escabra; pálea superior ausente. Cariopse $1,6-2 \times 0,5-0,8 \mathrm{~mm}$, castanho-escura na maturação. Espiguetas pediceladas neutras; glumas inferiores 2$3 \mathrm{~mm}$ compr., escabras ao longo das quilhas; glumas superiores ausentes.

Distribui-se do México, Guatemala, Honduras, Panamá, Paraguai, Uruguai, Argentina e Brasil: Rio de Janeiro, São Paulo, Rio Grande do Sul e Santa Catarina (Marchi \& Longhi-Wagner 1998; Flores 2001). Na Ilha de Santa Catarina foi encontrada no centro da cidade e nas margens da Avenida Beira Mar Norte, em gramados tratados de prédios e estacionamentos. Foi encontrada com flor e/ou fruto em maio e outubro.

Bothriochloa laguroides var. laguroides diferencia-se de $B$. exaristata especialmente por possuir espiguetas sésseis aristadas com lema superior presente. Apresenta hábito frequentemente semi-decumbente, o que pode ocorrer também em B. exaristata, no entanto seu porte é menor e suas folhas mais longas e concentradas na base dos colmos. 
Bothriochloa laguroides apresenta duas variedades, B. laguroides var. laguroides e $B$. laguroides var. torreyana, porém somente a primeira foi encontrada na Ilha de Santa Catarina.

Considerando que $B$. laguroides var. laguroides foi coletada apenas em áreas do centro da cidade e margens da Avenida Beira Mar Norte, acredita-se que a sua introdução na Ilha de Santa Catarina possa ter ocorrido através de meios de transporte, uma vez que encontra-se especialmente em locais onde a circulação de veículos é intensa.

Material examinado: BRASIL. Santa Catarina: Florianópolis, Centro, 04. V. 2009, B. Toncic \& A. Zanin 205, 206, 207 (FLOR); Beira-Mar Norte, 26. X. 2009, B. Toncic \& A. Zanin 247 (FLOR).

Material adicional examinado: BRASIL. Rio Grande do Sul: Pelotas, 07. XII. 1990, H. M. Longhi-Wagner et al. 2161 (FLOR); Porto Alegre, Morro da Polícia, 3. II. 1999, H. M. Longhi-Wagner \& A. Zanin 5058 (FLOR).

\section{Referências}

Caruso, M.M.L. 1990. O desmatamento da Ilha de Santa Catarina de 1500 aos dias atuais. Florianópolis: Editora da UFSC.

Centro de Estudos Cultura e Cidadania - CECCA. 1997. Unidades de Conservação e Áreas Protegidas da Ilha de Santa Catarina: caracterização e legislação. Florianópolis: Editora Insular.

Clayton, W.D. \& Renvoize, S.A. 1986. Genera graminum: grasses of the world. Kew: Royal Botanical Garden.

Flores, A.I.P. 2001. Bothriochloa. In: Longhi-Wagner,H. M.; Brittrich, V.; Wanderley, M.G.L. \& Shepherd, G.J. (Eds.). Poaceae. Flora Fanerogâmica do Estado de São Paulo. São Paulo: Hucitec. vol.1. p. 96-97.

Marchi, M.M. \& Longhi-Wagner, H.M. 1998. Gramineae: Andropogoneae. Boletim do Instituto de Biociências 57: 1-99. (Flora Ilustrada do Rio Grande do Sul 24).

Renvoize, S. 1998. Gramineas de Bolivia. Kew: Royal Botanic Gardens.

Smith, L.B., Wasshausen, D.C. \& Klein, R.M. 1982. Gramíneas. In: Reitz, R. (Ed.).

Flora Ilustrada Catarinense (Gram.). Itajaí: Herbário Barbosa Rodrigues.

Valls, J.F.M. 2010. Bothriochloa. In: Lista de Espécies da Flora do Brasil. Jardim Botânico do Rio de Janeiro. http://floradobrasil.jbrj.gov.br/2010/FB013058.

Vega, A.S. 2000. Revisión taxonômica de las espécies americanas del gênero Bothriochloa (Poaceae: Panicoideae: Andropogoneae). Darwiniana 38(1-2):127186. 


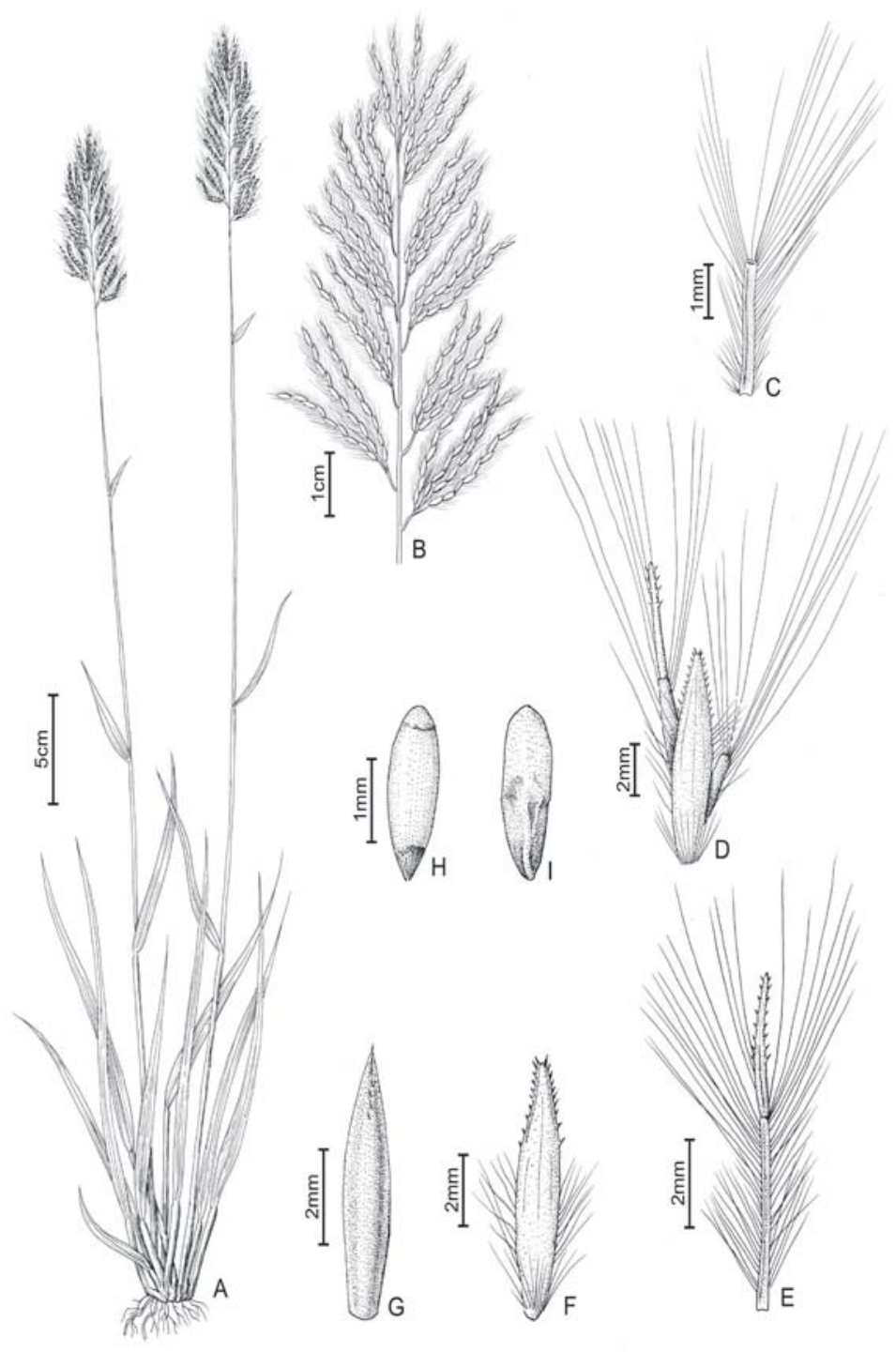

Figura 1.Bothriochloa exaristata. A. hábito;B. inflorescência; C. entrenó da ráquis;D. diásporo mediano do ramo florífero; E. espigueta pedicelada; F. espigueta séssil, vista da gluma inferior; G. gluma superior da espigueta séssil em vista dorsal; H. cariopse em vista ventral; I. cariopse em vista dorsal. (A-I: B. Toncic \& A. Zanin 232). 


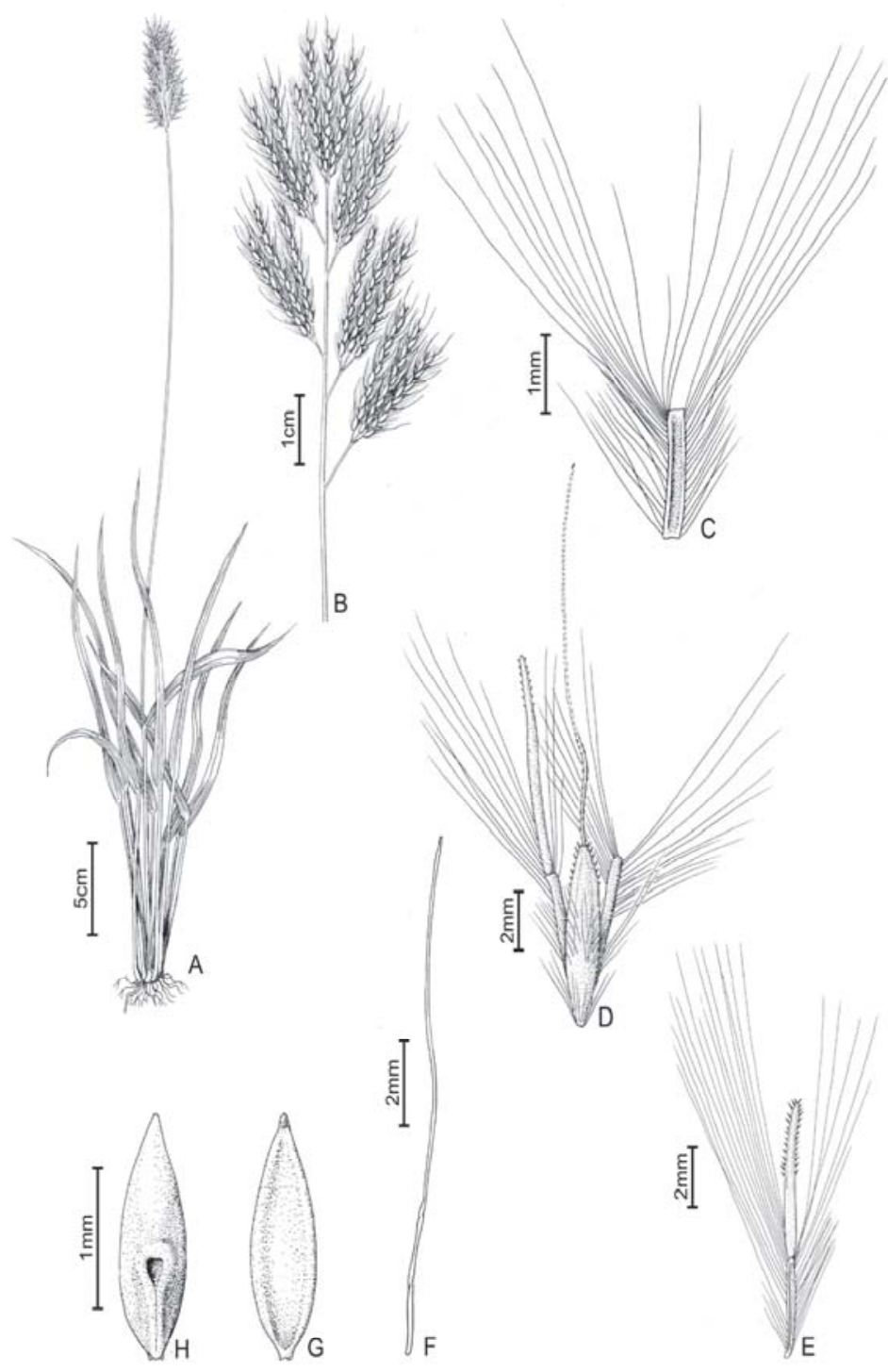

Figura 2. Bothriochloa laguroides var. laguroides. A. hábito; B. inflorescência; C. entrenó da ráquis; D. diásporo mediano do ramo florífero; E. espigueta pedicelada; F. lema superior da espigueta séssil aristado; G. cariopse em vista ventral; H. cariopse em vista dorsal. (A-H: B. Toncic \& A. Zanin 205). 